\title{
Group Awareness in Computer-Supported Collaborative Learning Environments
}

\author{
Hajar Ghadirian ${ }^{1}$, Ahmad Fauzi Mohd Ayub ${ }^{1}$, Abu Daud Silong ${ }^{2}$, Kamariah Binti Abu Bakar ${ }^{3} \&$ \\ Maryam Hosseinzadeh ${ }^{2}$ \\ ${ }^{1}$ Department of Foundation of Education, Faculty of Educational Studies, University Putra Malaysia, Serdang, \\ Selangor Darul Ehsan, Malaysia \\ 2 Department of Professional Development and Continuing Education, Faculty of Educational Studies, \\ University Putra Malaysia, Serdang, Selangor Darul Ehsan, Malaysia \\ ${ }^{3}$ Institute for Mathematical Research, University Putra Malaysia, Serdang, Selangor Darul Ehsan, Malaysia \\ Correspondence: Ahmad Fauzi Mohd Ayub, Department of Foundation of Education, Faculty of Educational \\ Studies, University Putra Malaysia, 43400 UPM, Serdang, Selangor Darul Ehsan, Malaysia. Tel: 60-19-664-6575. \\ E-mail: ahmad_fauzim@hotmail.com
}

Received: June 6, 2015 Accepted: July 20, 2015 Online Published: January 25, 2016

doi:10.5539/ies.v9n2p120 URL: http://dx.doi.org/10.5539/ies.v9n2p120

\begin{abstract}
It is commonly discussed that a key challenge for online collaboration is to promote group awareness. Although this challenge has gained intensified consideration by scholars, scarce attempt has been devoted into development of a reasonable hypothetical comprehension of what group awareness really is and how it can be studied empirically. This paper discusses the conceptions and the research approaches that underlie research on group awareness in computer-supported collaborative learning circumstances. While reviewing literatures they were classified in three categories (behavioral, knowledge and social awareness) and variations in underlying techniques for visualization of awareness were also provided. It was found that research is dominated by the knowledge awareness, which focus on awareness of self and group members' level of expertise, skills, prior knowledge of task as well as areas of interest. However, some researchers studied all dimensions of awareness. Findings suggest that the notion of displaying of awareness information has been shifted from implicit to the explicit technique through which users intentionally express their current understanding and feelings or assess self and others and provide necessary information to be visualized. The paper suggests some areas for future empirical investigations and concludes with some theoretical considerations on the nature of group awareness.
\end{abstract}

Keywords: group awareness, computer-supported collaborative learning (CSCL), knowledge awareness, social awareness, behavioral awareness

\section{Introduction}

A key challenge for online collaborative learning is to facilitate group awareness. Firstly, group awareness was discussed in the field of computer-supported cooperative work (CSCW) (e.g. Dourish \& Bellotti, 1992; Gutwin \& Greenberg, 2002) and then it became an increasingly investigated issue in the field of computer-supported collaborative learning (CSCL) (Bodemer \& Dehler, 2011). Approximately as long as computer-mediated communication (CMC) tools has been utilized, researchers have tried to discover how to overcome the barrios and deficiencies grounded in lack of face-to-face (F2F) interaction and reduced context and social cues through CMC tools. Dourish and Bellotti (1992) defined awareness as "an understanding of the activities of others, which provides a context to your own activity." Group awareness, then, refers to being informed about various aspects of the group and its members (Gross et al., 2005), such as what group members are doing and, where they are, what they are interested in, and how others feel about them. Generally, research on group awareness aims at developing tools that help members in gaining and utilizing such kind of person-related and group-related information that enables them to coordinate the content space as well as the relational space of collaboration (Bodemer \& Dehler, 2011).

In CMC settings and in the context of $\mathrm{CSCW}$, early technical solutions to provide awareness were triggering to rebuild the gold standard of $\mathrm{F} 2 \mathrm{~F}$ environments where members have access to a large amount of information 
(Jongsawat \& Premchaiswadi, 2011), e.g. through the use of video cameras that captured how work activities unfolded across space. In other words, typical awareness types were environmental or spatial cues received implicitly, in the sense of being aware of spatial activities and observable phenomena (presence, activities, and location) (Carroll et al. 2003). However, researchers suggested that awareness needs are different in environments of CSCL and CSCW (Buder, 2011). In CSCL emphasis is on collaboration rather than cooperation. So, Group awareness in CSCL approaches at fostering social and cognitive categories that are not directly observable (e.g. knowledge, attitudes, and intentions). In other words, in CSCL focus shifted from implicit information to explicit information (e.g. assessing and providing information about how a learning group evaluates the group members' contributions (Buder \& Bodemer, 2008).

A numbers of advantages have been reported by researchers regarding the group awareness information. For example, it is been suggested that group awareness orients the focus of collaboration toward higher level of communication where negotiation, elaboration and co-construction happen (El-Bishouty et al., 2010), improves the team effectiveness (Jongsawat \& Premchaiswadi, 2011), it can reduce group members' efforts to coordinate their actions, can increase their efficiency, and reduce the chance of errors (Gutwin \& Greenberg, 2004). Surprisingly, there is consensus among many researchers on the fact that group awareness is a key operator for learning process and team effectiveness in collaborative contexts even though their conceptualizations and techniques for facilitating that are very different. This study makes a comparison between two studies that have been done recently to illustrate this issue.

In the first study, Buder and Bodemer (2008) presented the development of a group awareness tool (GAT) that facilitates users to rate online contributions of others based on novelty and agreement, gathers these data, and visually represents the average agreement rating, and the average novelty rating that a given contribution captured. They examined relationship between utilization of GAT and group cognitive performance, interaction quality, learning achievement, and changes in rating data over time. Students' accesses to visualized data regarding how the group as a whole perceived their contributions was used to represent the group awareness which we later labels it as social awareness. Among other findings, it was concluded that "groups using an augmented GAT showed higher performance in terms of group decision and individual correctness than unsupported discussion groups" (p. 135).

In the second study, Phielix et al. (2010) searched for relationship between utilization of two augmented tools and group social and cognitive performance. The two complementary tools presented group members with information about social (reliability, cooperativeness, friendliness, and influence) and cognitive behavior (productivity) of their peers, themselves, and the group as a whole. Their study included the perspectives of the group members themselves (i.e. self perceptions), their peers (i.e. peer perceptions) and the group as a whole to represent group awareness in the form of social awareness. The findings indicated that "groups with Radar (Note 1) perceived their team as being better developed, experienced lower conflict levels, and had a more positive attitude towards collaborative problem solving than groups without Radar."

What can then be learnt about group awareness from the two studies above? To answer the question, one needs to investigate how group awareness was studied. Remarkably, scarce attempt has been devoted into evolving a reasonable comprehension of what group awareness really is and how it can be studies empirically. This paper aims to address this problem by providing a collection of awareness literature for three different types of awareness (behavioral, knowledge, and social awareness) reported by Bodemer and Dehler (2011). Generally, there are different classifications of types of group awareness for groupware applications. For example, Carroll et al. (2003) distinguish three kinds of awareness in CMC settings and point out that each one can be supported by certain tools: social awareness, action awareness, and activity awareness. However, as mentioned previously the contexts of CSCW and CSCL differ, so using Bodemer and Dehler's (2011) classification helps us in clarifying terminologies used in the context of CSCL for group awareness phenomenon. On this basis it purposes to symbolize broad areas of present CSCL-related research on group awareness in order to facilitate a comprehensive picture of how awareness information in CSCL research has been conceptualized and studied.

The paper is formed as follows. First, research procedure's description is provided, containing a discussion of how articles for review were selected and analyzed. Then, three different types of group awareness in the CSCL literature are discussed as well as their underling displaying techniques. This is followed by a description of the potential impacts of GATs in CSCL environments that is explained in the form of dependent variables. Finally, the findings, limitations, future research, and conclusions are put forward. 


\section{Procedure}

A literature review was conducted in order recognize papers that aim to examine group awareness. Taking notes from Webster and Watson (2002), search of literature was broadly on the topic rather than restricting the search to particular journals or years. Limiting search to particular journals or years might have affected the finding subjectively because not only specific journals might encourage particular research approaches, but also popularity of some research approach might have been higher within determined periods of time (Hrastinski \& Keller, 2007). Search of literature was initially conducted in the Education Resources Information Center (ERIC) database in January 2014. When identifying educational literature, one of the most considerable databases is ERIC because it contains well-known journals on CSCL that are published by organizations like Elsevier and Routledge (Hertzberg \& Rudner, 1999). It was searched for journal publications that comprised the words "group awareness," "social awareness," "behavioral awareness," "knowledge awareness," "group awareness tools," " social awareness tools," "behavioral awareness tools," and "awareness" in the title because these were perceived to analyze some aspect of group awareness. Totally, 1624 papers that contained each of these words in the title were found and 10 of these that evaluated group awareness features in CSCL were selected. Second phase of the literature review was conducted searching the bibliographies of the selected articles to find further articles including each of these words in their titles. 42 articles were further selected from the references parts of selected articles. However among them only 17 were related to the target of this paper. It was decided to only include articles that had at least one of the words mentioned above in the title because these were assumed to focus on the concept that this study wanted to scrutinize. Moreover, completion of such a review would have not been possible if searching criteria was not limited. A drawback of selected approach is that some beneficial articles were not identified. For instance, Kwon et al. (2013) examined group awareness but they did not use the words mentioned above in the title of their study. Appendix A displays the list of 27 articles selected for the purpose of this paper.

\section{What Is Group Awareness?}

In this section, examples of how group awareness information has been conceptualized, simulated and visualized, taken from the review of studies, are discussed. Clearly, review of studies shows that researchers' perceptions and strategies for visualization of group awareness information vary very much. Classification of articles was based on: 1) types of awareness, 2) techniques for displaying of awareness information (see Table 1 and appendix A), and 3) influenced factors (see Table 2 and appendix A) that each individual study utilized and examined. 
Table 1. Types of awareness and techniques for displaying of awareness information

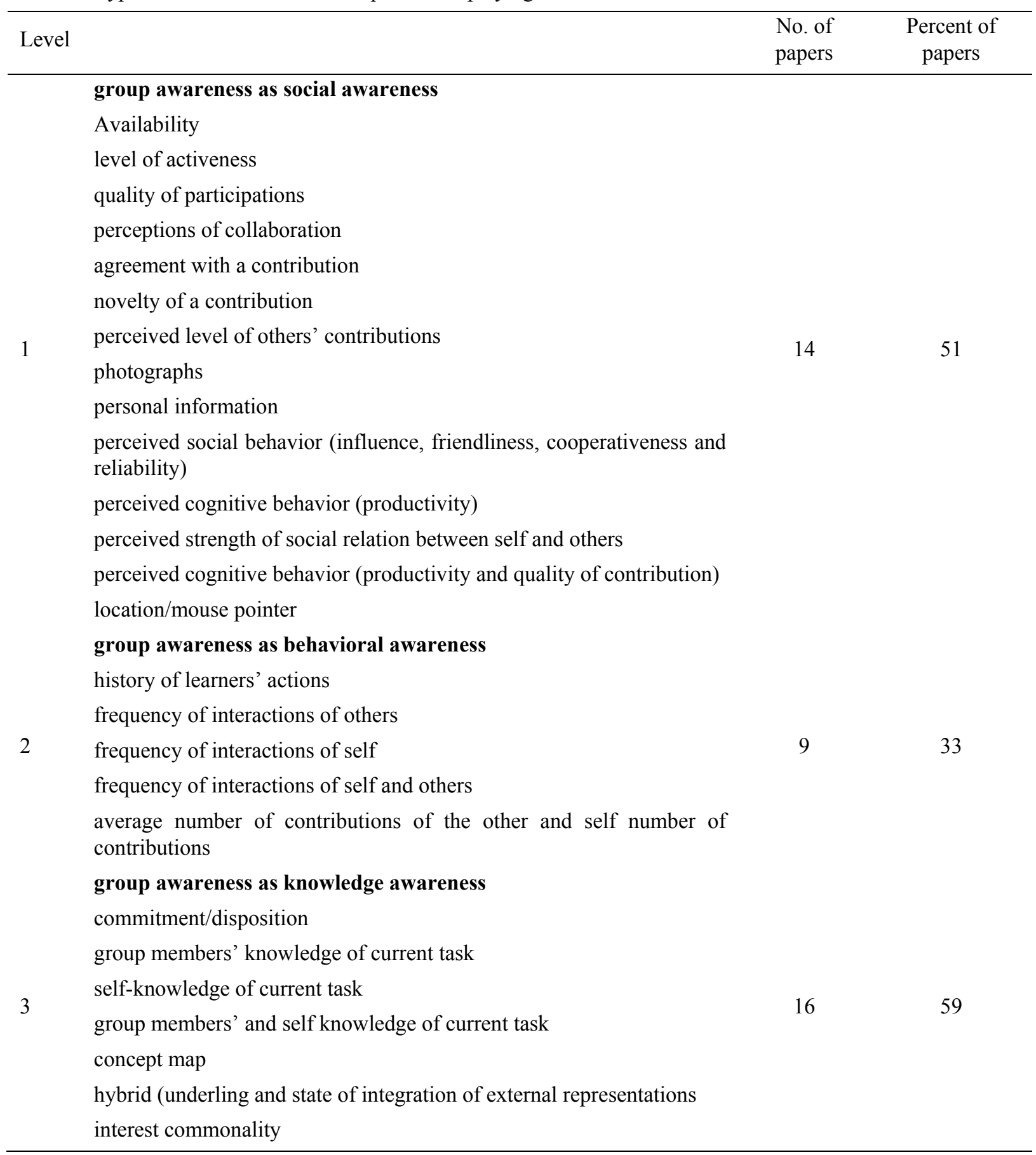

Data were calculated among 27 articles. 
Table 2. Reviewed articles by type of dependent variable

\begin{tabular}{lll}
\hline Dependent variables & No. of papers & Percent of papers \\
\hline Group cognitive performance & 10 & 37 \\
Group social performance & 5 & 19 \\
Quantity Of interaction & 6 & 22 \\
Interaction quality & 10 & 37 \\
Usability and Satisfaction & 8 & 30 \\
Individual achievement & 7 & 26 \\
Self-presentation & 1 & 3 \\
Tools usage & 1 & 3 \\
Transitive memory & 4 & 15 \\
Information sharing behaviors & 3 & 11 \\
Trust & 2 & 7 \\
Ratings data & 3 & 11 \\
\hline
\end{tabular}

\subsection{Level 1: Group Awareness as Social Awareness}

First level conceptions of group awareness deal with social awareness (SA). Prior researches have utilized different strategies to promote social awareness in the system. With social awareness, early researchers referred to the user's consciousness of the presence and availability of others (Carroll et al., 2003). A tool that makes the presence of others visible (e.g. by providing photographs of the team members, visualizing who is currently present, where he/she is located at the moment) can foster social awareness, implicitly. By "implicitly", it means that social awareness tools automatically generate awareness information without intervention of users. Carroll et al. (2003) mentioned that this facet of group awareness is equivalent to the social presence concept defined as senses of awareness of the presence of an interaction partner (Gunawardena, 1995; Short et al., 1976). Examples of this form of display are studies by Kimmerle and Cress (2007) (provision of personal photograph) and El-Bishouty et al. (2010) (provision of location).

However, in specific situations, such social awareness may not be adequate to support effective collaboration. In subsequent years, the notion of social awareness has been considerably extended to perceived functioning of self and group by the collaborators, and while Bodemer and Buder (2006) were among the first to theorize about this notion of social awareness. In contrast to implicit feedback system tools, social awareness tools with explicit feedback receive the necessary information explicitly and deliberately from users' recommendations, perceptions and ratings data to the actions of themselves (self-assessments), others (assessments of others) or both (self and others assessments) through survey questionnaire (Dehler et al., 2010; Phielix et al., 2010).

\subsection{Level 2: Group Awareness as Behavioral Awareness}

Conceptions of group awareness in the second level are specified by that group awareness is equaled with awareness of the up-to-minute knowledge of other peoples' activities, i.e. history of other members and self actions, frequency of interactions of others, frequency of interactions of self, and average number of contributions of the group. Basically, tools which support behavioral awareness (BA) mainly displays awareness information using implicit system which was mentioned in section 3.1. Basically, behavioral awareness tools provide objective awareness rather than subjective awareness. However, behavioral awareness tools can be considered as the most dynamic displaying awareness tools because they provide learners with up-to-minutes awareness information. Examples of behavioral awareness tools were employed by Janssen et al. (2011) and Janssen and Bodemer (2013).

\subsection{Level 3: Group Awareness as Knowledge or Cognitive Awareness}

Group awareness's conceptions in the third level are determined by that group awareness is equaled with awareness of self and group members' level of expertise, skills, prior knowledge of task as well as areas of interest. This dimension of group awareness has been currently entered in CSCL research and introduces awareness tools that provide information about cognitive states (Buder \& Bodemer, 2008).

Displaying of knowledge awareness information in knowledge awareness (KA) tools have been generated either 
explicitly (Engelmann et al., 2009) or implicitly (Ogata \& Yano, 2000). Moreover, knowledge awareness information was gained before group interaction meaning that such information was static. Referring to Appendix A, it is appetent that third level conceptions of group awareness have been progressively popular in recent years. Since 2008, 11 out of 17 articles $(65 \%)$ were qualified by these conceptions.

\section{Dependent Variables}

Reviewing the selected articles showed that different variables have been examined in accordance with group awareness information. It is perceived that addressed variables range from individual measures (learning achievement via test, self-presentation, and usability of system) to collectively constructed measures (group social and cognitive performance such as cohesion, conflict and so on). Some researchers even investigated variables that lie in the process of collaboration, among them are patterns and quality of interaction, information sharing behaviors (sharing intention and actual sharing behavior), and frequency of tool usage. As illustrated in Table 2, a vast majority of reviewed studies, 10 out of 27 examined the role of GATs (either of each) on group cognitive performance and quality of interaction (37\%) whilst only one article examined self-perception (3\%), as well as tool usage (3\%). Variables "usability and satisfaction," "individual achievement," "quantity of interaction," "group social performance," and "transitive memory" were examined by 8 (30\%), 7 (26\%), 6 (22\%), $5(19 \%)$, and $4(15 \%)$ articles, respectively. Only 3 articles investigated the effect of utilization of GATs on the information sharing behaviors $(11 \%)$, as well as ratings data (11\%). Trust was also considered in $2(7 \%)$ studies. Data shows that indicators of group performance were among the most investigated variables.

\section{Discussion}

In this paper, three types of conceptions of group awareness, varying from social awareness, behavioral awareness and knowledge awareness as well as the methods used for conceptualization and displaying of them, were explained. Moreover, the most common and frequently examined dependent variables in accordance with group awareness, ranging from group cognitive performance to group social performance, were identified. Review of articles showed that researchers have chosen different methods for displaying awareness information. However, there is no consensus among them that what method is more appropriate in a given context. Moreover, we found that none of the studies compared different dimensions of group awareness in order to suggest which dimension is more critical and fundamental than the others. The question, then, is if one type of awareness is advantageous with regard to collaborative learning.

Probably, each of the determined conceptions and approaches has its own advantages and limitations. For instance, if presuming that group awareness is parallel with explicit social and knowledge awareness, the result can be easily biased because some users may not assess self or others honestly. Moreover, forcing participants to rate their own and others may lead to lower acceptance of tool. That's while achieving such information especially those related to social awareness (such as friendliness and reliability) would be quite difficult and costly to be extracted through computerized means (e.g. latent semantic analysis of contents). However, if acknowledging group awareness as a complex phenomenon, where both explicit group awareness rated by participants and system should be used it becomes more difficult to visualize awareness because there may be discrepancy between what users assess of themselves with what system calculate.

In CSCL the first way of generating group awareness is naturally as the product of interaction by means of CMC tools. When a collaborator write contributions and participate in a group discussion, the other group members gain direct understandings from his/her activities and his/her availability. Although, the content of argument and its voice in a group discussion can make learners aware of their fellow partners' knowledge, opinion, emotional state, and satisfaction with the group work, gaining such shared understandings are hard to achieve in CSCL environments and may result in cognitive load. That's why GATs in CSCL contexts try to support learners with explicit awareness information. Result of review showed that $63 \%$ of displaying of awareness information is done explicitly (Table 3). Moreover, the concepts of "vicarious learning" and "social persuasion" recognize the fact that learners engaged in active dialogues are continuously learning through observation of others and receiving feedback from them (Bandura, 1986; McKendree et al., 1998). So, it can be discussed that an implication of the group awareness is that it might benefit learners from comparison of their level of activities, knowledge, opinions and so on with the other members of the group. Even more of studies examined the role of GATs on group cognitive performance; it is argued that they ignored the mechanisms through which GATs impacts on the group performance. In other words, it might be useful to find how interpersonal relationships and group process indicators mediate such relationships. 
Table 3. Methods of displaying of awareness information

\begin{tabular}{|c|c|c|c|}
\hline Explicit & Percent & Implicit & Percent \\
\hline $\begin{array}{l}\text { - level of activeness } \\
\text { - quality of participations } \\
\text { - perceptions of collaboration } \\
\text { - agreement with a contribution } \\
\text { - novelty of a contribution } \\
\text { - perceived level of others' contributions } \\
\text { - perceived social behavior (influence, friendliness, } \\
\text { cooperativeness and reliability) } \\
\text { - perceived cognitive behavior (productivity) } \\
\text { - perceived strength of social relation between self and } \\
\text { others } \\
\text { - perceived cognitive behavior (productivity and quality } \\
\text { of contribution) } \\
\text { - commitment/disposition } \\
\text { - group members' knowledge of current task } \\
\text { - self-knowledge of current task } \\
\text { - group members' and self knowledge of current task } \\
\text { concept map } \\
\text { - hybrid (underling and state of integration of external } \\
\text { representations }\end{array}$ & 63 & $\begin{array}{l}\text { - Availability } \\
\text { - photographs } \\
\text { - personal information } \\
\text { - history of learners' } \\
\text { actions } \\
\text { - frequency of } \\
\text { interactions of others } \\
\text { - frequency of } \\
\text { interactions of self } \\
\text { - frequency of } \\
\text { interactions of self } \\
\text { and others } \\
\text { - average number of } \\
\text { contributions of the } \\
\text { other and self } \\
\text { number of } \\
\text { contributions } \\
\text { - interest } \\
\text { commonality }\end{array}$ & 34 \\
\hline
\end{tabular}

\subsection{Limitations and Future Research}

Based on the fact that recognized research approaches and conceptions were relying on 27 articles out of many publications, it does not inevitably indicate research on group awareness in general but, nonetheless, provides a sign of recent research applications. Moreover, publications which were published in formats such as books, dissertations, conference proceedings, and review papers were not included in this study. The categorization of conceptions could have been assembled in other ways which are more common in CSCW environments. The review of literature in this paper only included studies that explicitly focused on group awareness in CSCL environments.

Future research can focus on designing GATs that visualize different dimensions of group awareness and examine which dimension is more critical and supportive on a specific context. The other possible area of research is comparing the explicit and implicit forms of displaying of awareness information. Moreover, high-level conceptions of group awareness may be studied through a research framework that include not only examination of GATs on group and individual outcomes, but also consider how social interpersonal variables and group process indicators mediate such relationships.

\section{Conclusion}

This paper has reviewed the underling research approaches and conceptions commonly covered in group awareness research in CSCL settings. While the variety of settings and tools makes it hard to provide a clear-cut and comprehensive definition of group awareness, it also underlies that group awareness is likely to stay an active field of research in the context of CSCL. It was found that GATs are dominated by knowledge awareness tools, which rely on awareness of self and group members' level of expertise, skills, prior knowledge of task as well as areas of interest generated either explicitly or implicitly. The findings also displayed that many researchers prefer explicit feedback systems, mainly because awareness information is gained subjectively. However, this paper discusses that even though some researchers have visualized more than one dimensions of group awareness but, they did not compared different awareness tools in order to realize which one is more useful in a certain context. Moreover, it was argued that there are many areas left unexplored in accordance with 
group awareness, among many are "how to make a balance between explicit and implicit displaying of awareness information," "how group process indicators mediate relationship between GATs' utilization and group performance."

\section{References}

Bandura, A. (1986). Social foundations of thought and action. Englewood Cliffs, NJ: Prentice-Hall.

Beaudouin-Lafon, M. (1994). Beyond the workstation: Mediaspaces and augmented reality. In G. Cockton, S. W. Draper, \& G. R. S. Weir (Proc. HCI'94), (pp. 9-18). Cambridge University Press.

Bodemer, D., \& Buder, J. (2006). Supporting collaborative learning with augmented group awareness tools. In R. Sun, \& N. Miyake (Eds.), Proceedings of the Twenty-Eighth Annual Conference of the Cognitive Science Society (pp. 77-82). Mahwah, NJ: Erlbaum.

Bodemer, D., \& Dehler, J. (2011). Group awareness in CSCL environments. Computers in Human Behavior, 27(3), 1043-1045. http://dx.doi.org/10.1016/j.chb.2010.07.014

Buder, J. (2011). Group awareness tools for learning: Current and future directions. Computers in Human Behavior, 27(3), 1114-1117. http://dx.doi.org/10.1016/j.chb.2010.07.012

Buder, J., \& Bodemer, D. (2008). Supporting controversial CSCL discussions with augmented group awareness tools. International Journal of Computer-Supported Collaborative Learning, 3(2), 123-139. http://dx.doi.org/10.1007/s11412-008-9037-5

Carroll, J. M., Neale, D. C., Isenhour, P. L., Rosson, M. B., \& McCrickard, D. S. (2003). Notification and awareness: synchronizing task-oriented collaborative activity. International Journal of Human-Computer Studies, 58(5), 605-632. http://dx.doi.org/10.1016/S1071-5819(03)00024-7

Dehler-Zufferey, J., Bodemer, D., Buder, J., \& Hesse, F. W. (2010). Partner knowledge awareness in knowledge communication: Learning by adapting to the partner. The Journal of Experimental Education, 79(1), 102-125. http://dx.doi.org/10.1080/00220970903292991

Dehler, J., Bodemer, D., Buder, J., \& Hesse, F. W. (2009). Providing group knowledge awareness in computer supported collaborative learning: Insights into learning mechanisms. Research and Practice in Technology Enhanced Learning, 4(02), 111-132. http://dx.doi.org/10.1142/S1793206809000660

Dehler, J., Bodemer, D., Buder, J., \& Hesse, F. W. (2011). Guiding knowledge communication in CSCL via group knowledge awareness. Computers in Human Behavior, 27(3), 1068-1078. http://dx.doi.org/10.1016/j.chb.2010.05.018

Dourish, P., \& Bellotti, V. (1992). Awareness and coordination in shared work spaces. Paper presented at the ACM conference on Computer supported cooperative work (CSCW'92), Toronto, Canada.

El-Bishouty, M. M., Ogata, H., Rahman, S., \& Yano, Y. (2010). Social Knowledge Awareness Map for Computer Supported Ubiquitous Learning Environment. Educational Technology \& Society, 13(4), 27-37.

Engelmann, T., Dehler, J., Bodemer, D., \& Buder, J. (2009). Knowledge awareness in CSCL: A psychological perspective. Computers in Human Behavior, 25(4), 949-960. http://dx.doi.org/10.1016/j.chb.2009.04.004

Engelmann, T., Tergan, S.-O., \& Hesse, F. W. (2009). Evoking knowledge and information awareness for enhancing computer-supported collaborative problem solving. The Journal of Experimental Education, 78(2), 268-290. http://dx.doi.org/10.1080/00220970903292850

Fransen, J., Kirschner, P. A., \& Erkens, G. (2011). Mediating team effectiveness in the context of collaborative learning: The importance of team and task awareness. Computers in Human Behavior, 27(3), 1103-1113. http://dx.doi.org/10.1016/j.chb.2010.05.017

Gross, T., Stary, C., \& Totter, A. (2005). User-centered awareness in computer-supported cooperative work-systems: Structured embedding of findings from social sciences. International Journal of Human-Computer Interaction, 18(3), 323-360. http://dx.doi.org/10.1207/s15327590ijhc1803_5

Gunawardena, C. N. (1995). Social presence theory and implications for interaction and collaborative learning in computer conferences. International journal of educational telecommunications, 1(2), 147-166.

Gutwin, C., \& Greenberg, S. (2002). A descriptive framework of workspace awareness for real-time groupware. Computer Supported Cooperative Work (CSCW), 11(3-4), 411-446. http://dx.doi.org/10.1023/A:1021271517844

Hertzberg, S., \& Rudner, L. (1999). Quality of Researchers' Searches of the ERIC Database. Education Policy 
Analysis Archives, 7(25).

Hrastinski, S., \& Keller, C. (2007). An examination of research approaches that underlie research on educational technology: A review from 2000 to 2004. Journal of Educational Computing Research, 36(2), 175-190. http://dx.doi.org/10.2190/H16L-4662-6000-0446

Janssen, J., \& Bodemer, D. (2013). Coordinated computer-supported collaborative learning: Awareness and awareness tools. Educational Psychologist, 48(1), 40-55. http://dx.doi.org/10.1080/00461520.2012.749153

Janssen, J., Erkens, G., \& Kirschner, P. A. (2011). Group awareness tools: It's what you do with it that matters. Computers in Human Behavior, 27(3), 1046-1058. http://dx.doi.org/10.1016/j.chb.2010.06.002

Jongsawat, N., \& Premchaiswadi, W. (2011). A study of two different experimental settings for group awareness information in a web-based group decision support system. International Journal of Information Technology \& Decision Making, 10(2), 231-268. http://dx.doi.org/10.1142/S0219622011004312

Kimmerle, J., \& Cress, U. (2007). Group awareness and self-presentation in the information-exchange dilemma: An interactional approach. In C. Chinn, G. Erkens, \& S. Puntambekar (Eds.), Proceedings of the 7th computer supported collaborative learning conference (pp. 367-374). New Brunswick, Inc: International Society of the Learning Sciences.

Kimmerle, J., \& Cress, U. (2008). Group awareness and self-presentation in computer-supported information exchange. International Journal of Computer-Supported Collaborative Learning, 3(1), 85-97. http://dx.doi.org/10.1007/s11412-007-9027-z

Kimmerle, J., Cress, U., \& Hesse, F. W. (2007). An interactional perspective on group awareness: Alleviating the information-exchange dilemma (for everybody?). International Journal of Human-Computer Studies, 65(11), 899-910. http://dx.doi.org/10.1016/j.ijhcs.2007.06.002

Kwon, K., Hong, R.-Y., \& Laffey, J. M. (2013). The educational impact of metacognitive group coordination in computer-supported collaborative learning. Computers in Human Behavior, 29(4), 1271-1281. http://dx.doi.org/10.1016/j.chb.2013.01.003

Lambropoulos, N., Faulkner, X., \& Culwin, F. (2012). Supporting social awareness in collaborative e-learning. British Journal of Educational Technology, 43(2), 295-306. http://dx.doi.org/10.1111/j.1467-8535.2011.01184.x

McKendree, J., Stenning, K., Mayes, T., Lee, J., \& Cox, R. (1998). Why observing a dialogue may benefit learning. Journal of Computer Assisted Learning, 14(2), 110-119. http://dx.doi.org/10.1046/j.1365-2729.1998.1420110.x

Ogata, H., \& Yano, Y. (1998). Supporting awareness for augmenting participation in collaborative learning. Proceedings of Ed-Media '98 (On-line). Retrieved Febrary 1st, 2014, from http://www-yano.is.tokushima-u.ac.jp/ogata/ papers.html

Ogata, H., \& Yano, Y. (2000). Combining knowledge awareness and information filtering in an open-ended collaborative learning environment. International Journal of Artificial Intelligence in Education (IJAIED), $11,33-46$.

Ogata, H., \& Yano, Y. (2004). Knowledge awareness map for computer-supported ubiquitous language-learning. Paper presented at the Wireless and Mobile Technologies in Education. Procceeding of IEEE WMTE 2004, 19-26.

Ogata, H., Matsuura, K., \& Yano, Y. (1996). Sharlok: Bridging learners through active knowledge awareness. Proceedings of IEEE Systems Man \& Cybernetics, 1, 601.

Phielix, C., Prins, F. J., \& Kirschner, P. A. (2010). Awareness of group performance in a CSCL-environment: Effects of peer feedback and reflection. Computers in Human Behavior, 26(2), 151-161. http://dx.doi.org/10.1016/j.chb.2009.10.011

Phielix, C., Prins, F. J., Kirschner, P. A., Erkens, G., \& Jaspers, J. (2011). Group awareness of social and cognitive performance in a CSCL environment: Effects of a peer feedback and reflection tool. Computers in Human Behavior, 27(3), 1087-1102. http://dx.doi.org/10.1016/j.chb.2010.06.024

Ray, D. G., Neugebauer, J., Sassenberg, K., Buder, J., \& Hesse, F. W. (2013). Motivated shortcomings in explanation: The role of comparative self-evaluation and awareness of explanation recipient's knowledge. Journal of Experimental Psychology: General, 142(2), 445. http://dx.doi.org/10.1037/a0029339 
Romero-Salcedo, M., Osuna-Gómez, C. A., Sheremetov, L., Villa, L., Morales, C., Rocha, L., \& Chi, M. (2004). Study and analysis of workspace awareness in CDebate: a groupware application for collaborative debates. Interacting with Computers, 16(4), 657-681. http://dx.doi.org/10.1016/j.intcom.2004.07.004

Sangin, M., Molinari, G., Nüssli, M.-A., \& Dillenbourg, P. (2011). Facilitating peer knowledge modeling: Effects of a knowledge awareness tool on collaborative learning outcomes and processes. Computers in Human Behavior, 27(3), 1059-1067. http://dx.doi.org/10.1016/j.chb.2010.05.032

Schreiber, M., \& Engelmann, T. (2010). Knowledge and information awareness for initiating transactive memory system processes of computer-supported collaborating ad hoc groups. Computers in Human Behavior, 26(6), 1701-1709. http://dx.doi.org/10.1016/j.chb.2010.06.019

Short, J., Williams, E., \& Christie, B. (1976). The social psychology of telecommunications. John Wiley, London, United Kingdom.

Webster, J., \& Watson, R. T. (2002). ANALYZING THE PAST TO PREPARE FOR THE FUTURE: WRITING A. Mis Quarterly, 26(2).

\section{Note}

Note 1. Radar is the name of GA tool.

\section{Appendix A}

\section{Taxonomy of articles}

\begin{tabular}{|c|c|c|c|c|c|c|c|c|c|c|c|c|c|}
\hline source & level & $\begin{array}{l}\text { Group } \\
\text { cognitive } \\
\text { performance }\end{array}$ & $\begin{array}{l}\text { Group social } \\
\text { performance }\end{array}$ & $\begin{array}{l}\text { Quantity } \\
\text { of } \\
\text { interaction }\end{array}$ & $\begin{array}{l}\text { Intreaction } \\
\text { quality }\end{array}$ & $\begin{array}{l}\text { Usability } \\
\text { and } \\
\text { Satisfaction }\end{array}$ & $\begin{array}{l}\text { Individual } \\
\text { achievement }\end{array}$ & $\begin{array}{l}\text { Self-presenta } \\
\text { tion }\end{array}$ & $\begin{array}{l}\text { Tools } \\
\text { usage }\end{array}$ & $\begin{array}{l}\text { Transactive } \\
\text { memory }\end{array}$ & $\begin{array}{l}\text { Information } \\
\text { sharing } \\
\text { behaviors }\end{array}$ & trust & $\begin{array}{c}\text { Ratings } \\
\text { data }\end{array}$ \\
\hline $\begin{array}{l}\text { Jongsawat } \\
\text { and } \\
\text { Premchaisw } \\
\text { adi (2011) }\end{array}$ & $\begin{array}{l}1 \mathrm{~A} \\
1 \mathrm{~B} \\
3 \mathrm{~A}\end{array}$ & $v$ & $\checkmark$ & v & & & & & & & & & \\
\hline $\begin{array}{l}\text { El-Bishouty } \\
\text { et al. (2010) }\end{array}$ & $\begin{array}{l}1 \mathrm{~L} \\
1 \mathrm{~N} \\
3 \mathrm{~B}\end{array}$ & & & v & $\checkmark$ & $\checkmark$ & & & & & & & \\
\hline $\begin{array}{l}\text { Lambropou } \\
\text { los et al. } \\
\text { (2012) }\end{array}$ & $\begin{array}{l}1 \mathrm{C} \\
2 \mathrm{D}\end{array}$ & & & v & $v$ & $v$ & & & & & & & \\
\hline $\begin{array}{l}\text { Janssen and } \\
\text { Bodemer } \\
\text { (2013) }\end{array}$ & $\begin{array}{l}\mathrm{IC} \\
1 \mathrm{D} \\
{ }_{2 \mathrm{~B}} \\
{ }_{3 \mathrm{~B}}\end{array}$ & v & & & & & $v$ & & & & & & \\
\hline $\begin{array}{l}\text { Ogata } \\
\text { andYano } \\
\text { (1998) }\end{array}$ & $2 \mathrm{~A}$ & & & $v$ & & & & & & & & & \\
\hline $\begin{array}{l}\text { Kimmerle } \\
\text { and Cress } \\
\text { (2008) }\end{array}$ & $\begin{array}{l}2 \mathrm{D} \\
2 \mathrm{E}\end{array}$ & & & & & & & $\checkmark$ & & & & & \\
\hline $\begin{array}{l}\text { Buder and } \\
\text { Bodemer }\end{array}$ & $\begin{array}{l}{ }^{1 E} \\
{ }_{1 F}\end{array}$ & v & & & $v$ & & $v$ & & & & & & v \\
\hline
\end{tabular}




\begin{tabular}{|c|c|c|c|c|c|c|c|c|c|c|c|}
\hline \multicolumn{12}{|c|}{ (2008) } \\
\hline \multicolumn{12}{|l|}{ Zufferey } \\
\hline & $3 \mathrm{D}$ & & & & $\checkmark$ & & $\checkmark$ & & & & \\
\hline \multicolumn{12}{|l|}{ et al. (2010) } \\
\hline \multicolumn{12}{|l|}{ Bishouty et } \\
\hline & $3 \mathrm{~B}$ & & & & & $\sqrt{ }$ & $\checkmark$ & & & & \\
\hline \multicolumn{12}{|l|}{ al. (2007) } \\
\hline \multirow[t]{2}{*}{ Ray et al. } & 3B3 & & & & & & & & & & \\
\hline & & $\sqrt{ }$ & & & & & & $\sqrt{ }$ & $\checkmark$ & & \\
\hline \multirow[t]{2}{*}{ (2013) } & C3D & & & & & & & & & & \\
\hline & $1 \mathrm{~N}$ & & & & & & & & & & \\
\hline Ogata et al. & $2 \mathrm{~A}$ & & & & & & & & & & \\
\hline \multirow[t]{2}{*}{ (1996) } & $2 \mathrm{D}$ & & & & & & & & & & \\
\hline & $3 \mathrm{~A}$ & & & & & & & & & & \\
\hline Kimmerle & $1 \mathrm{H} 1 \mathrm{I}$ & & & & & & & & & & \\
\hline and Cress & $2 \mathrm{D} 2$ & & & & & & & & $\checkmark$ & $\checkmark$ & \\
\hline (2007) & $\mathrm{E}$ & & & & & & & & & & \\
\hline \multicolumn{12}{|l|}{ Dehler et al. } \\
\hline & $3 \mathrm{D}$ & & & & $\checkmark$ & $\sqrt{ }$ & $\checkmark$ & $\sqrt{ }$ & & & \\
\hline \multicolumn{12}{|l|}{ (2011) } \\
\hline Engelmann & 3D3 & & & & & & & & & & \\
\hline et al. (2009) & $\mathrm{E} 3 \mathrm{~F}$ & & & & & & & & & & \\
\hline Kimmerle & & & & & & & & & & & \\
\hline and Cress & $2 \mathrm{D}$ & & & & & & & & $\checkmark$ & & \\
\hline & $2 \mathrm{E}$ & & & & & & & & & & \\
\hline (2007) & & & & & & & & & & & \\
\hline Phielix et & $1 \mathrm{~J}$ & & & & & & & & & & \\
\hline & & $\checkmark$ & $\checkmark$ & & & & & & & & \\
\hline al. (2010) & $1 \mathrm{~K}$ & & & & & & & & & & \\
\hline Bodemer & & & & & & & & & & & \\
\hline & $1 \mathrm{E}$ & & & & & & & & & & \\
\hline and Buder & & $\sqrt{ }$ & & $\sqrt{ }$ & $\sqrt{ }$ & & & & & & $\checkmark$ \\
\hline & $1 \mathrm{~F}$ & & & & & & & & & & \\
\hline (2006) & & & & & & & & & & & \\
\hline Janssen et & & & & & & & & & & & \\
\hline & $1 \mathrm{G}$ & $\checkmark$ & & $\checkmark$ & $\checkmark$ & & & $\checkmark$ & & & \\
\hline al. (2011) & & & & & & & & & & & \\
\hline Engelmann & & & & & & & & & & & \\
\hline & $3 \mathrm{E}$ & $\checkmark$ & $\checkmark$ & & & & & $\checkmark$ & & & \\
\hline et al. (2009) & & & & & & & & & & & \\
\hline Schreiber & & & & & & & & & & & \\
\hline and & & & & & & & & & & & \\
\hline & $3 \mathrm{E}$ & $\checkmark$ & & & & & & $\checkmark$ & & & \\
\hline Engelmann & & & & & & & & & & & \\
\hline (2010) & & & & & & & & & & & \\
\hline Phielix et & $1 \mathrm{~J}$ & & & & & & & & & & \\
\hline & & $\checkmark$ & $\sqrt{ }$ & & $\checkmark$ & & & & & & $\checkmark$ \\
\hline al. (2011) & $1 \mathrm{M}$ & & & & & & & & & & \\
\hline Romero-Sal & $1 \mathrm{~A}$ & & & & & & & & & & \\
\hline cedo et al. & $1 \mathrm{E}$ & & $\sqrt{ }$ & & & $\sqrt{ }$ & & & & & \\
\hline (2004) & $1 \mathrm{~N}$ & & & & & & & & & & \\
\hline Sangin et & & & & & & & & & & & \\
\hline & $3 \mathrm{~B}$ & & & & $\checkmark$ & & $\checkmark$ & & & $\checkmark$ & \\
\hline al. (2011) & & & & & & & & & & & \\
\hline El-Bishoute & $1 \mathrm{~N}$ & & & & & & & & & & \\
\hline & & & & & & $\checkmark$ & & & & & \\
\hline t al. (2006) & 3B & & & & & & & & & & \\
\hline
\end{tabular}




\begin{tabular}{lll}
\hline Ogata & 2A & \\
andYano & 3A & $\checkmark$ \\
$(2000)$ & 3G & \\
\hline & 1N & $\checkmark$ \\
Ogata and & 2A & \\
Yano & 3A & \\
(2004) & 3E & \\
\hline Dehler et al. & 3G & \\
(2009) & 3D & $\checkmark$ \\
\hline
\end{tabular}

\section{Copyrights}

Copyright for this article is retained by the author(s), with first publication rights granted to the journal.

This is an open-access article distributed under the terms and conditions of the Creative Commons Attribution license (http://creativecommons.org/licenses/by/3.0/). 